\title{
CLIMATIC VARIABLES AND MASS BALANCE OF ALPINE GLACIERS DURING A PERIOD OF CLIMATE FLUCTUATION
}

\author{
(Abstract)
}

by

David N. Collins

(Department of Geography, University of Manchester, Manchester M13 9PL, U.K.)

\begin{abstract}
Parameterisation of relationships between climate and glacier mass balance is of considerable importance in understanding and modelling how temporal variability in climate affects the quantity of perennial snow and ice stored in glaciers, and the runoff from glacierised areas. Influences of year-to-year variations in air temperatures are pertinent in the absence of long records of measured energy balance and in view of predictions of future climate scenarios in terms of temperature. Measurements of temperature and precipitation from several stations in Alpine valleys in the Rhone basin, Wallis, Switzerland have been analysed to indicate trends in climate from 1930 to 1988. Actual measurements of mass balance of Griesgletscher, ablation calculated from runoff and net accumulation estimated from totalising rain gauges for Findelengletscher and Gornergletscher beginning in the late 1960s, and runoff from Aletschgletscher since 1930, were taken as annual glaciological responses to climatic variation. Variables to represent climatic elements and interactions between precipitation and temperature were selected according to degree of correlation with glacier response variables, and climate-glacier response relationships were assessed by multiple regression. Subsets of the data representing the coolest (1972-81) and warmest (1943-52) decades were also analysed to indicate whether relationships amongst climatic variables and between climate and mass balance remain the same under contrasting climatic conditions.
\end{abstract}

Overall, mean summer air temperature variables for the months May through September and June through August provide the highest levels of explanation of variance of ablation and mass balance respectively $(75-82 \%)$. Addition of a precipitation variable (winter, spring or summer) in multiple regression increases explanation to a maximum of $91 \%$. Spring and summer precipitation variables are negatively correlated with ablation. Positive degree days and temperature-summer snow functions provide alternatives to temperature. Event-based analysis of the coolest and warmest years selected by rank order invokes high precipitation in May and low May-June temperatures and summer snowfall events as significant variables.

Relationships between climatic variables indicate that warmer-than-average winters have higher precipitation, but at summer and annual time scales precipitation is slightly negatively associated with temperature. At the decadal level, warmer periods appear to be influenced by increased frequency of continental anticyclonic conditions, in an area subject to both maritime and continental influences. These analyses of climatic variables indicate that summer energy inputs dominate glacier mass balance. Relationships between precipitation and temperature are complex and were changeable during a fluctuation of about $1^{\circ}$ over 40 years. Effects of a potentially warmer future on the form of precipitation in spring, summer and autumn are not clear, so estimates of changes of mass balance have been calculated for contrasting precipitation regimes.

\section{EVALUATION OF LANDSAT, SPOT, AND SOJUZKARTA DATA OF ANTARCTICA FOR ICE AND CLIMATE RESEARCH}

\author{
(Abstract) \\ by \\ Jane G. Ferrigno and Bruce F. Molnia
}

(U.S. Geological Survey, 927 National Center, Reston, VA 22092, U.S.A.)

Satellite data have proved suitable and cost-effective for ice and climate research in Antarctica. They have been used in numerous research efforts, including: monitoring coastal change, determining velocities of outlet glaciers, defining blue ice areas, tracking the movement of icebergs, and as a base for overlaying radar and other data. This paper reviews the data acquired since 1972 by the Landsat, SPOT and Sojuzkarta space systems and illustrates where good-quality $( \pm 10 \%$ cloud cover $)$ data are available.

The Landsat 1,2 , and 3 satellites acquired approximately 10000 multispectral scanner (MSS) ( $80 \mathrm{~m}$ resolution) and return-beam vidicon (RBV) (30 m resolution) photo- graphic and digital images of Antarctica between 1972 and 1983. The quality of these images has been evaluated by USGS to determine the feasibility of using them for glaciological, climatological, and geological research. Results have been plotted on a base map of Antarctica and show about $45 \%$ of the nominal scene centers, or about $70 \%$ of the geographic area of the continent, to be covered by good-quality imagery. Landsat 4 started acquiring data in 1982 and Landsat 5 in 1984. Together the two satellites acquired more than 4500 thematic mapper (TM) (30 m resolution) and MSS images of Antarctica through the 1988-89 austral summer season, which may be the last 
season of Landsat 4 and 5 acquisition. The majority of the scenes have been acquired by two major projects: the West German Institut für Angewandte Geodäsie project to acquire data from the Ronne Ice Shelf area to the Greenwich meridian, and the USGS project to acquire data of coastal Antarctica and the inland boundary of the ice shelves, for use by the Scientific Committee on Antarctic Research (SCAR) community. Landsat 4 and 5 have different orbital parameters from Landsat 1,2 , and 3 . As a result Landsat 4 and 5 imagery have different areal coverage. The data also have been archived differently. While the Landsat 1,2 , and 3 data exist in film format, many Landsat 4 and 5 TM images exist only as high-density digital tapes, and, as a result, the scenes cannot be examined and evaluated before purchase. Computer evaluation of the Landsat 4 and 5 data indicate that about 1350 or about $30 \%$ of the images have $10 \%$ cloud cover or less. However, it is difficult for automatic systems or those unfamiliar with the area to discriminate between clouds and snow. Based on a sampling of the data, it is more likely that $10-15 \%$, or about 500 scenes, are of good quality. Those scenes which have been examined and evaluated as part of the SCAR cooperative acquisition project and are known to be of good quality are plotted and compared with the earlier Landsat data. The combined plot gives accurate and reliable information on the location of good quality Landsat 1-5 data of Antarctica.

More than 7000 Sojuzkarta scenes have been collected over Antarctica since 1976. The most useful data consist of photography from the KATE-200 system ( $20 \mathrm{~m}$ resolution) and the KFA-1000 system ( $6 \mathrm{~m}$ resolution). The data have been plotted by the U.S. Geological Survey and will soon be available as an open-file report. Those scenes which have been evaluated as having $10 \%$ cloud cover or less are plotted separately and overlaid on the Landsat plots. Scenes which have been examined are excellent, but an insufficient number of scenes have been inspected to evaluate the accuracy of the cloud cover estimation.

The Système Probatoire d'Observation de la Terre (SPOT) was launched in 1986 and has acquired more than 1200 scenes of Antarctica. SPOT data consist of multispectral $(20 \mathrm{~m}$ resolution) and panchromatic ( $10 \mathrm{~m}$ resolution) photographic or digital imagery. SPOT also possesses a mechanical plane mirror which permits off-nadir imaging and the generation of stereoscopic images. The locations of these scenes are now being plotted by the U.S. Geological Survey. Scenes with $10 \%$ cloud cover or less will be combined with Landsat and Sojuzkarta data to provide an accurate summary of the availability and coverage of highquality satellite data of Antarctica.

\title{
POTENTIAL FOR BASAL MELTING UNDER THE SUMMIT CORING SITE, CENTRAL GREENLAND
}

\author{
(Abstract)
}

by

John Firestone, Ed Waddington and Jim Cunningham

(Geophysics Program AK-50, University of Washington, Seattle, WA 98195, U.S.A.)

The climatic record from Greenland boreholes is likely to extend well beyond the last interglacial only if the basal ice near the drilling sites has never reached its pressure melting point $\left(-2^{\circ} \mathrm{C}\right)$. A simplified one-dimensional analysis (Paterson and Waddington, 1986) suggested that this would be true at Crête, Greenland, if the geothermal flux was less than $48 \mathrm{~mW} \mathrm{~m}^{-2}$. In that study, the vertical velocity pattern for an isothermal ice sheet was used. We have repeated the Crête calculations using the vertical velocity pattern derived by a finite element analysis. Using this temperaturedependent velocity pattern lowered the basal temperature by about $3{ }^{\circ} \mathrm{C}$

We have carried out a similar analysis for the Summit coring site further north on the Greenland ice divide. Here we find that the basal ice does not melt if the geothermal flux is less than $54 \mathrm{~mW} \mathrm{~m}^{-2}$, using the same mass balance and surface temperature histories as the previous study. We are repeating these one-dimensional calculations with more recently compiled histories and plan to present results from a full two-dimensional temperature model that includes a full two-dimensional temperature model that in the one-dimensional models. Using two dimensions, we will more realistically incorporate the special ice-flow patterns found at divides (e.g. Raymond, 1983; Dahl-Jensen, 1989). In steady-state flow models these patterns lead to significant horizontal temperature gradients and a "hot spot" beneath an ice divide (Paterson and Waddington, 1986). In addition, we will more accurately determine the transient effects on basal temperature resulting from the interaction of these flow patterns and the changing climate. Our discussion will include sensitivity to geothermal heat flux, ice thickness and paleoenvironmental history.

\section{REFERENCES}

Dahl-Jensen, D. 1989. Steady thermomechanical flow along two-dimensional flow lines in large grounded ice sheets. J. Geophys. Res., 94(B4), 10,355-10,362.

Paterson, W.S.B. and E.D. Waddington. 1986. Estimated basal ice temperature at Crête, Greenland, throughout a glacial cycle. Cold Reg. Sci. Technol., 12(1), 99-102.

Raymond, C.F. 1983. Deformation in the vicinity of ice divides. J. Glaciol., 29(103), 357-373. 